\title{
Sporadic and Familial Variants in NF1: An Explanation of the Wide Variability in Neurocognitive Phenotype?
}

\begin{abstract}
Maëlle Biotteau ${ }^{1,2 \star}$, Sébastien Déjean ${ }^{3}$, Sandrine Lelong ${ }^{2}$, Stéphanie lannuzzi ${ }^{2}$, Nathalie Faure-Marie ${ }^{2}$, Pierre Castelnau ${ }^{4,5,6}$, François Rivier ${ }^{7}$, Valérie Lauwers-Cancès ${ }^{8}$, Eloïse Baudou ${ }^{1,2}$ and Yves Chaix ${ }^{1,2}$

${ }^{1}$ ToNIC, Toulouse Neurolmaging Center, University of Toulouse, Inserm, UPS, Toulouse, France, ${ }^{2}$ Children's Hospital, Toulouse-Purpan University Hospital, Toulouse, France, ${ }^{3}$ Institut de Mathématiques de Toulouse, UMR5219 Université de Toulouse, CNRS UPS, Toulouse, France, ${ }^{4}$ UMR 1253, iBrain, University of Tours, INSERM, Tours, France, ${ }^{5}$ Department of Medicine, University of Tours Francois Rabelais, Tours, France, ${ }^{6}$ Pediatric Neurology, Clocheville Children's Hospital, Tours University Hospital, Tours, France, ${ }^{7}$ Department of Pediatric Neurology and Reference Center for Language Disabilities, CHU Montpellier, PhyMedExp, University of Montpellier, INSERM, CNRS, Montpellier, France, ${ }^{8}$ Epidemiology Department, Toulouse University Hospital, Toulouse, France
\end{abstract}

\section{OPEN ACCESS}

Edited by:

Michele Roccella,

University of Palermo, Italy

Reviewed by:

Maurizio Elia,

Oasi Research Institute (IRCCS), Italy

Marco Carotenuto,

University of Campania Luigi

Vanvitelli, Italy

*Correspondence:

Maëlle Biotteau

maelle.biotteau@inserm.fr

Specialty section:

This article was submitted to

Pediatric Neurology

a section of the journal

Frontiers in Neurology

Received: 03 March 2020

Accepted: 14 April 2020

Published: 05 May 2020

Citation:

Biotteau M, Déjean S, Lelong S,

lannuzzi S, Faure-Marie N,

Castelnau P, Rivier F,

Lauwers-Cancès V, Baudou $E$ and

Chaix Y (2020) Sporadic and Familial Variants in NF1: An Explanation of the

Wide Variability in Neurocognitive

Phenotype? Front. Neurol. 11:368.

doi: 10.3389/fneur.2020.00368
Background: Cognitive impairment is the most common neurological manifestation in NF1 and occurs in 30-70\% of NF1 cases. The onset and severity of each specific cognitive deficit varies greatly from child to child, with no apparent external causes. The wide variability of phenotype is the most complex aspect in terms of management and care. Despite multiple research, the mechanism underlying the high heterogeneity in NF1 has not yet been elucidated. While many studies have focused on the effects of specific and precise genetic mutations on the NF1 phenotype, little has been done on the impact of NF1 transmission (sporadic vs. familial cases). We used a complete neuropsychological evaluation designed to assess five large cognitive areas: general cognitive functions (WISC-IV and EVIP); reading skills ("L'Alouette," ODEDYS-2 and Lobrot French reading tests); phonological process (ODEDYS-2 test); visual perceptual skills (JLO, Thurstone and Corsi block tests) and attention (CPT-II), as well as psychosocial adjustments (CBCL) to explore the impact of NF1 transmission on cognitive disease manifestation in 96 children affected by NF1 [55 sporadic cases (29o, 260 $)$; 41 familial cases $\left(24 \rho, 170^{7}\right)$ ].

Results: Familial and Sporadic form of NF1 only differ in IQ expression. The families' socioeconomic status (SES) impacts IQ performance but not differently between sporadic and familial variants. However, SES is lower in familial variants than in the sporadic variant of NF1. No other cognitive differences emerge between sporadic and familial NF1.

Conclusions: Inheritance in NF1 failed to explain the phenotype variability in its entirety. IQ differences between groups seems in part linked to the environment where the child grows up. Children with NF1, and especially those that have early diagnoses (most often in inherited cases), must obtain careful monitoring from their 
early childhood, at home to strengthen investment in education and in school to early detect emerging academic problems and to quickly place them into care.

Trial Registration: IDRCB, IDRCB2008-A01444-51. Registered 19 January 2009.

Keywords: NF1, child, cognitive profile, sporadic, familial, hereditary, SES

\section{HIGHLIGHTS}

- Familial and Sporadic form of NF1 differ in IQ expression

- SES impacts IQ performance but not differently between sporadic and familial variants

- SES is lower in familial variants than in the sporadic variant of NF1

- No other cognitive differences emerge between sporadic and familial NF1

- Inheritance in NF1 failed to explain the phenotype variability in its entirety.

\section{BACKGROUND}

\section{Clinical Features of NF1}

Neurofibromatosis type 1 (NF1 or also von Recklinghausen's disease), is a tumor predisposition syndrome characterized by the development of typical cutaneous and ophthalmologic manifestations including cafe-au-lait spots, freckling, dermal neurofibromas and Lisch nodules. NF1 patients may also develop endocrine (early-onset puberty, growth retardation), neurological (learning disabilities, epilepsy), ophthalmological (optic glioma), skeletal (bone dysplasia, scoliosis), cosmetic disfigurement or organ compression due to plexiform neurofibromas and vascular complications (high blood pressure) (1-5). NF1 patients are at increased risk of developing various tumors or characteristic malignancy (malignant peripheral nerve sheath tumor or other malignancies such as intracranial astrocytomas, gastrointestinal stromal tumors, pheochromocytomas, juvenilemonocytic leukemia, leukemia, glioma, rhabdomyosarcoma, and breast cancer) $(1,3,6)$.

The NF1 phenotype (clinical presentation) is highly variable in expression $(7,8)$. First, clinical manifestations are progressive and age dependent. They appear gradually during childhood, from cafe-au-lait macules at birth, to skinfold freckles, then lisch nodules and latter neurofibromas (2). Most of the complications persist into adulthood. Second, even if penetrance is complete in children over 8 years old (9), clinical features range from a very mild manifestation to a very severe form of the disease depending of individuals.

Cognitive impairment is the most common neurological manifestation in NF1 and occurs in $30-70 \%$ of NF1 cases (10). Studies characterizing the neuropsychological phenotype of NF1 children have highlighted some strong well-established features (11-17). Clinical studies have revealed a left shift in average IQ, ranging from low to normal IQ. Severe intellectual disability (IQ < 70) is however unusual, occurring in only about $5 \%$ of patients $(10,18-20)$. Children with NF1 are also at increased risk for difficulties with specific cognitive functions: attention, executive function, reading, expressive and receptive language, language cues interpretation, working memory, visual spatial perception, psychomotor skills (10-14, 21-26). Many school-age NF1 children also experience marked difficulties in learning and academic areas and also presented with learning disorders (reading, mathematics/arithmetic, and written expression). Impaired, poor performance on reading or spelling tasks, deficits, defects in visual-spatial and visual-perceptual skills are therefore common (12). The onset and severity of each specific cognitive deficit varies greatly from child to child, with no apparent external causes. The authors tried to link radiologic specific features in NF1 such as T2 hyperintensities to cognitive impairment (27). In almost 75\% of cases, NF1 children present with T2-hyperintensities (4) located mainly in the basal ganglia, thalamus, brainstem and cerebellum, which usually resolve in early adulthood and probably reflect intramyelinic oedema (28). Although the presence and number of T2-hyperintensities do not seem to be related to possible cognitive disorders, some authors find a correlation between IQ scores and their thalamic (29) or cerebellar (30) localization, with an improvement of IQ score with resolving T2-hyperintensities (31). As T2-hyperintensities do not explain the specific cognitive deficits encountered in $\mathrm{NF} 1$, authors try to correlate finer structural cerebral changes as higher cerebral volumes or global altered diffusion without further success. Thus, the neuronal substratum of NF1 cognitive phenotype remains unclear.

These cognitive problems do not worsen with age but do not resolve either. They were among the most common manifestation to negatively affect quality of life in NF1 (32-36), leading to significant impacts upon scholastic performance, vocational and professional guidance $(37,38)$.

\section{Diagnosis}

Despite advances in understanding the genetics of NF1, clinical diagnoses are often made based on physical characteristics [National Institutes of Health Consensus Development Conference Statement -NIH, 1988 (39) for formal diagnostic criteria for NF1, later reaffirmed in 1997], including cutaneous, ophthalmologic, and orthopedic features $(1,40,41)$ see Box 1.

\section{Genetic}

NF1 is one of the most common childhood neurogenetic disorders worldwide, affecting approximately 1 in every 2,500 to 3,500 individuals $(42,43)$. It is caused by mutations in the NF1 gene, a classic tumor suppressor gene (44) on chromosome 17 (17q11.2) which encodes neurofibromin that is largely expressed in the nervous system (45-47). The most of NF1 gene lesions 
BOX 1 | National Institutes of Health (NIH) diagnostic criteria for neurofibromatosis type 1 (NF1) (39).

The clinical diagnosis is based on the presence of two or more major disease features out of the following:

- Six or more café-au-lait macules $>5 \mathrm{~mm}$ in greatest diameter in prepubescent individuals, and $>15 \mathrm{~mm}$ in post-pubescent individuals

- Two or more neurofibromas of any type or one plexiform neurofibroma

- Freckling in the axillary or inguinal regions

- Optic glioma

- Two or more iris hamartoma (Lisch nodules)

- Distinctive bony lesion such as sphenoid dysplasia, or thinning of the long bone cortex with or without pseudoarthrosis

- A first-degree relative (parent, sibling, or offspring) with NF1 based on the above criteria

inhibit the expression of intact neurofibromin. Neurofibromin belongs to a family of proteins that act as negative regulators of the ras oncogene and serves as a tumor suppressor $(43,48,49)$. Disruption of neurofibromin explains why NF1 patients are at risk for developing tumors.

NF1 is an autosomal dominantly inherited disease, which means that when one of the parents has the disease, there is a one in two chance of transmitting NF1 to an offspring (1). However, although NF1 is an autosomal dominant condition, about 50 percent of NF1 cases are due to new mutations $(42,50)$ resulting from a de novo mutation. The NF1 gene exhibits a very high new mutation rate [between $3-5 \times 10^{-5}$ and $1.4-2.6 \times 10^{-4}$, $(51,52)]$, among the highest observed in humans, 10 times higher than is typical for human disease gene loci (53). The NF1 gene is one of the largest human genes, with about 350 kilobases of genomics DNA, containing 61 exons to encode 2,839 amino acids and producing an 11-12.5 kilobase messenger RNA containing an open reading frame of 8,454 nucleotides $(45,54,55)$. However, neither the size nor the complexity of the NF1 gene are sufficient to account for this unusually high new mutation rate (56).

Sporadic cases (consequence of new mutations) occur in the absence of a NF1 family history. It may be difficult to distinguish clinically mosaic NF1 individuals from NF1 individuals with an inherited NF1. It has been noted that more than one sporadic case can be observed in several families, each with a distinct NF1 mutation $(57,58)$. There are also some rare cases of parental mosaicism for an NF1 mutation, comprising germline mutation (59-61). In this situation, the parents do not carry the disease but one of them carries the genetic anomaly in some of their reproductive cells. Such individuals (considering as having a mosaic NF1) have a weaker but unquantifiable risk of passing on generalized NF1 to an offspring. Parental mosaicism is also considered as a sporadic case $(62,63)$. It should be noted that the frequency of NF1 mosaicism in the population may be underestimated since some mosaic individuals may have no clinical evidence of NF1 (63).

Given that the development of congenital syndromes and cancer predisposition are associated with advanced maternal or paternal age (64), research has been done on NF1 (65-67) but has lead to conflicting reports and lesser association between age and de novo mutations. As in several other autosomal dominant disorders, paternal age has been mentioned to explain sporadic cases. However, although the average age of fathers of children with sporadic NF1 was more often higher than fathers in the general population $(65,66)$, effect of age to de novo mutation is small or non-existent (68). In addition, several studies have suggested that $90 \%$ of spontaneous mutations in NF1 originate in the paternal genome $(46,69)$. Kaplan et al. (63) found that mutated allele (R1968X, recurrent variant present in 1 to $2 \%$ of individuals with NF1) is of maternal origin.

\section{Care Management}

The wide variability of phenotype both between individuals with NF1 and within NF1 families is the most complex aspect in terms of management and care. Clinical features and presentation of NF1 are extremely variable $(7,8)$ and involve many of the body systems. The complications of NF1 differ depending on the individual concerned (presence vs. absence of each possible symptom) and variation in their expressions (minimal, mild, moderate, or severe) is considerable and highly heterogenic. In addition, clinical presentation is unpredictable even within the same family $(1,52)$, including the age of disease onset and the severity of clinical symptoms (70, 71). For example, Upadhyaya et al. (58) report the genetic analysis of a unique family with NF1, in which the three affected members had a different heritable and pathological mutations in their NF1 genes and exhibited different clinical evidence of NF1. In familial form, the severity of manifestations in a child cannot be expected by a parent's clinical course (or other family members) and the risk of having a seriously ill child is 1 in 12 (1). Members of the same family and even more, identical twins with NF1, often exhibit variable syndrome expression. Thus, twin studies, which have been a respected tool for studying genetic disorders, were not conclusive in the NF1 literature reports. Numerous studies have presented monozygotic twins, both affected by NF1 but differing in their phenotypes $(62,72)$. Kaplan et al. (63) also presented monozygotic twin discordant for autosomal disorder NF1 (unaffected twin that show no clinical manifestations) who is therefore considered as a mosaic even if the distribution of the mutant allele among different cells and tissues seems insufficient to induce clinical manifestations of NF1. Detjen et al. (62) did not detect any mitochondrial DNA differences between individuals of the same twin pair, highlighting that mitochondrial DNA polymorphisms [an obvious candidate for an extrachromosomal phenotype modifier (73)] do not seem to contribute to the phenotypic variability in NF1.

Copy number variants research (CNVs) also failed to understand phenotypic variability (74). In their study, the authors analyze CNVs in 11 pairs of monozygotic twins with several phenotypic discordances and concordances to identify genetic factors potentially affecting disease manifestation but found no differences in CNVs that could justify discordant NF1 characteristics (74).

A recent study (68) found that there is no significant effect of parental age on the incidence of NF1 or the coexistence of different NF1 symptoms, or on their level. The authors also did 
not find any relationship between sex and clinical symptoms, although previous study have showed that sex can be a key influence for neural dysfunction in NF1 (75).

With the exception of deleting the entire NF1 gene which is associated with a very severe form of disease (76), clinical manifestations are irrespective of the causative genetic alterations (77): most studies thus showed no relationship between the particular NF1 mutation type (whether they are missense/nonsense, point mutations, splicing, micro- or gross-deletions, micro- or gross-insertions, duplications, etc.) and the expression of clinical manifestations in NF1 individuals. Cognitive deficits encountered in NF1 are no exception to this rule and such uncertainty and lack of knowledge on why complications of NF1 differ depending on the individuals concerned is exactly the same for cognitive impairments (78).

This very high variability of the NF1 phenotype, including for individuals carrying the same NFl gene mutation, suggests that other factors (other modifying genes, epigenetic influences, second hit somatic mutations in the NF1 gene, hormonal milieu, but also environmental factors or chance) might be involved in the clinical expression of the NF1 phenotype and might be the reason behind this phenomenon $(71,79,80)$. Little is however known about such relative contributions.

The management of NF1 children is therefore mainly based on follow-up, in order to detect possible complications such as behavioral or cognitive deficit as soon as possible since early care significantly improves skills and abilities. This uncertainty is a source of stress and anxiety for families and establishing prognostic factors could help professionals responsible for the follow-up of these patients.

\section{Aims and Objectives}

Despite multiple and serious research, the mechanism underlying the wide variability in NF1 has not yet been elucidated. Prospective identification and screening of such individuals is currently not possible. There is currently no way to measure, predict or know which NF1 patients will develop one or several symptoms but not others (and why), or which NF1 patients will develop complications or not. However, identifying factors that modify the NF1 phenotype may greatly help to improve patient counseling.

Brain development is based on the ongoing interaction of innate biological determinants and environmental determinants that will modulate the organization, structuring and functioning of the brain. In our study, we therefore ask if the mode of transmission (and consequently the environmental determinants) can influence the cognitive phenotype in NF1 patients.

Indeed, while many studies have focused on the effects of high specific and high precise genetic mutations on the NF1 phenotype, little has been done on the impact of NF1 transmission (sporadic vs. familial cases). This question of transmission establishes a solid framework to study environmental factors, the social level in which the child evolves, the detection of disease and diagnosis (which may be earlier in family forms), the difficulties of informing parents of the clinical status of their child and the consequences of such a disclosure [given that pessimism is less common in familial than in sporadic NF1 (36)], etc.

The issue of influence between sporadic or familial onset on cognitive profile of affected NF1 individuals was not extensively discussed. Learning disabilities, which are very frequent in NF1, is however one of the chief factors in the deterioration of quality of life in NF1 patients $(10,36)$, both in children and adults since they lead to poor school academic performances, preclude individuals to higher education and graduate school, lower the education level and restrict individuals' choices and their professional future. They also cause great damage to self-image, the development of assertiveness and independence.

In this study, we used a large set of cognitive performance abilities (attention, reading, intellectual, and visual-spatial skills), as well as psychosocial adjustments to explore the impact of NF1 transmission (sporadic vs. familial cases) on cognitive disease manifestation in 96 children affected by NF1 [ 55 sporadic cases $\left(29 \%, 26 \sigma^{\top}\right) ; 41$ familial cases $\left.\left(24 \%, 17 \sigma^{\top}\right)\right]$.

\section{METHODS}

\section{Participants}

The participants included 55 children with sporadic NF1 expression and 41 children with the familial NF1 variant, all aged between 8 and 12 years old. Patients with a family history of neurofibromatosis type 1 or a first-degree relative with one criteria of neurofibromatosis type 1 , according to the $\mathrm{NIH}$ criteria, were classified as having the familial variant. Patients without any familial history of neurofibromatosis type 1 were classified as having the sporadic variant. Seventy-five of them had been previously included in a published study on the cognitive profile of NF1 (81). NF1 subjects were recruited from the existing NF1 patient population at six French national NF1 referral centers (Children's Hospitals of Lyon, Montpellier, Nantes, Paris, Toulouse, and Tours). Inclusion criteria were (1) age between 8 and 12 years and (2) a confirmed clinical diagnosis of NF1 according to the NIH criteria (39). MRI examination was not required for inclusion but if it had been done, symptomatic optic glioma was considered to be an exclusion criterion. Children with a known major medical, neurological or psychiatric disorder that could potentially affect cognition (epilepsy, brain tumor, hydrocephalus, head injury, autism, or intellectual disability with an IQ below 70) or with uncorrectable hearing or visual impairment were excluded.

All parents and children gave their informed oral and written consent, after the nature and objectives of the study were thoroughly explained. Approval to conduct this study was granted by the French Ministry of Health's Hospital Programme for Clinical Research (PHRC 2008, Toulouse University Hospital, no. 08113 01), Occitanie Regional Council (APRTC no. 09004813), and the local Ethics Committee (CPP Southwest, France) in accordance with the Declaration of Helsinki convention.

\section{Procedure}

Participation in the study was offered to parents by a pediatric neurologist through a clinic for follow-up. A leaflet describing the 
characteristics of the study, a recruitment letter, a consent form and a demographic/health screening questionnaire were directly given or sent to them later.

All the children were received for two half-day sessions. They underwent a medical examination to exclude ADHD and other neurological and psychiatric diseases, and to confirm the NF1 diagnosis. Then, all the children underwent the same complete five-part individual, neuropsychological evaluation conducted by certified clinical neuropsychologists, using a comprehensive and large protocol designed to assess five large cognitive areas: general cognitive functions; reading skills; phonological process; visual perceptual skills and attention. Each area was composed of several tests which were given in a specific and the same order as part of a neuropsychological battery. However, the order of administration of the five large cognitive areas was randomly changed between subjects to minimize the order bias of the neuropsychological assessment results (81).

\section{Measures}

This study fits in with a larger project [methodology described in Chaix et al. (81). Each participant was assessed with a comprehensive battery of standardized psychometric tests including (i) all subtests of the Wechsler Intelligence Scale for Children-Fourth Edition [WISC-IV (82)]; and the French version of the "Peabody Picture Vocabulary Test-Revised" [EVIP (83)] for the cognitive assessment; (ii) the "Alouette" French reading test [revised version (84)], the ODEDYS-2 test (85) and the ORLEC battery (86) for the reading and phonological skills assessment; (iii) the Judgment of Line Orientation test (87), the Thurstone test and the Corsi blocks for visual perceptual assessment; and (iv) the Conners Continuous Performance Test-Second Edition (88) and the parent form Child Behavior CheckList (CBCL) questionnaire (89) for the attention and psychosocial skills assessment. All the assessments were conducted in French. French norms were used to calculate scores for all children wherever available.

The issue of the socio-cultural characteristics (occupation and educational level of parents) has also been raised.

Cognitive abilities were assessed with the French-language version of the WISC-IV (82) designed for children between the ages of 6 to 16. In this psychological assessment, four primary Index make up the Full Scale IQ score (Verbal Comprehension Index -VCI, Perceptual Reasoning Index -PRI, Working Memory Index -WMI, and Processing Speed Index -PSI Scores; themselves calculated from several subtests). The core 10 subtests include Comprehension, Similarities, and Vocabulary subtests for the VCI; Block design, Picture concepts and Matrix reasoning for the PRI; Digit span and Letter-number sequencing for the WMI Coding and Symbol search for the PSI. Raw scores were converted to age-scaled scores (standard scores for subtests $\mathrm{M}$ $=10, \mathrm{SD}=3$; standard scores for index and full scale IQ: $\mathrm{M}$ $=100, \mathrm{SD}=15)$. All subtests and indexes have demonstrated good reliability and validity and are considered good measures of general intelligence.

Reading disorders were evaluated with the "L'Alouette" French reading test (84), the most widely used reading test in French-speaking countries. The "L'Alouette" test is currently used as the "gold standard" test by health care professionals (especially speech therapists) and researchers to screen for reading level (good or poor readers, dyslexia) among children and adolescents. Reading text assessment was completed by word recognition procedures, measured by the "Word Reading" subtest from the ODEDYS-2 test (85). Phonological processing (phonological memory and phonemic awareness) was measured with three tests from the ODEDYS-2 battery of tests (85) (1) pseudoword repetition task (phonological short-term memory), (2) phonemic deletion task (phonemic awareness), and (3) blending task or acronyms task (phonemic awareness). Reading comprehension efficiency for both sentences and text was assessed through a standardized reading comprehension test, the ORLEC battery (86). The first subtest (L1) consists of text to be read aloud. The second subtest (L3) is silent reading comprehension test with a forced-choice sentence completion test.

Receptive lexical skills were determined by the French version of the "Peabody Picture Vocabulary Test-Revised" (EVIP) (83). EVIP is intended to provide a quick estimate of the receptive vocabulary ability of children from the ages of 2.6 to 18 years old.

Sustained attention and impulsivity capacities were measured by the Conners Continuous Performance TestSecond Edition (88). CPT-II is a computer-administered neuropsychological task used to evaluate the attentional functioning (sustained attention and impulsivity) of individuals aged at least 6 years old. It is commonly used in research and by clinical means for discriminating inattentive, hyperactive, and impulsive behavior difficulties in children via target vs. non-target stimuli designed to have minimal language and memory demands. The CPT-II leads to 12 outcome measures but we only analyzed the four main scores: Omissions (number of non-responses to target), commissions (number of responses to non-target stimuli), hit reaction time (measure of response speed consistency), and perseverations (measure of response inhibition).

Psychosocial adjustments were assessed with the parent form of the Child Behavior CheckList (CBCL) questionnaire (89). The $\mathrm{CBCL}$ is a parent-report measure of behavioral and emotional problems for children aged 6 to 18 years used in both clinical and research practice. It lists internalizing and externalizing symptoms of 113 child behaviors.

Visual perceptual abilities were assessed with the Judgment of Line Orientation test (JLO) (87) and the Thurstone test. The JLO test measures a person's ability to match the angle and orientation of lines in space using a task that consists of matching two angled lines that appear at the top of a page, to the angles of two lines among a standard fan-shaped array (semicircle) of 11 lines (separated 18 degrees from each other) appearing at the bottom of the page. The Thurstone's Identical Form Test measures certain capacities of visual and spatial perception. For this test, the visual-spatial component is predominant. Visualspatial memory was assessed by determining forward and backward spans with the Corsi blocks-tapping test.

Socioeconomic status of the parents (SES): Both parents of the participants were asked about their profession and level of education. We coded the professions into eight categories according to the classification of professions and socioprofessional categories established by the National Institute 
of Statistics and Economic Studies (Institut national de la statistique et des sciences économiques, INSEE) in 1982. This statistical classification, that allows professions to be classified, exists at an aggregate level of eight positions (1. Farmers, farm operator; 2. Artisans, traders and entrepreneurs; 3. Employees and higher intellectual professions; 4. Intermediate professions; 5. Employees; 6. Workers 7. Pensioner; 8. Other individuals without activity professional) but is also developed in 24 and 42 positions (with correspondence between the three nomenclatures). This nomenclature allows the grouping of individuals into homogeneous social categories according to their professional activity, on the basis of three main criteria: the hierarchical position within the profession performed (completed by the level of diploma required to practice this profession), the status (employee or self-employed), and the nature of the activity (agricultural or non-agricultural).

To this nomenclature, we added a classification of the level of education in 5 gradients: (1) Without diploma or "Brevet des colleges"; (2) CAP or BEP; (3) General, technological or vocational baccalaureate (around 18 years); (4) Diploma 2 years after baccalaureate; (5) Graduate and postgraduate diplomas (Bachelor's degree, Master's degree).

\section{Statistical Analysis}

As a first screening step, statistical tests were conducted for every numerical variable to compare the two sub-groups: sporadic and familial. Both Student and Wilcoxon-MannWhitney rank-sum tests were run as a way to ensure the relevance of the results. In order to study the effect of socioeconomic status on the previous results, 5-factor ANOVAs were conducted for each numerical variable. These analyses included the NF1 form as well as the level of education and the profession of the two parents. To make it easier to interpret the results, no interaction factors were included in the models. As the mother's level of education appeared as the SES variable with the highest effect, further investigation focused on this factor jointly with the NF1 form. Twofactor ANOVA with interaction were then conducted to assess the potential cross effect of these two factors. Every analysis was performed using the $\mathrm{R}$ software (version 3.5.2, released 2018-12-20).

\section{RESULTS}

\section{General Characteristic of the Population}

The 96 children included in the main analysis were part of this exploratory analysis. Demographic (age, sex) and socioeconomic status variables (level of education and profession of the two parents) are presented in Table 1. The population is roughly balanced between the sporadic NF1 variant (55) and the familial variant (41). This proportion allowed statistical comparison between the two groups to be considered. The two groups were homogeneous with no differences in terms of age or gender. Factors that could influence cognitive ability (socioeconomic status of the father and mother: parental educational level and
TABLE 1 | Demographic and Social Characteristics of the Sporadic and Familial Groups.

\begin{tabular}{|c|c|c|c|}
\hline & \multicolumn{2}{|c|}{ 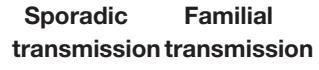 } & \multirow[t]{2}{*}{$P$-value } \\
\hline & $N=55$ & $N=41$ & \\
\hline \multicolumn{4}{|l|}{ Demographic characteristics } \\
\hline Age in years [Mean (SD)] & $9.8(1.4)$ & $10.2(1.3)$ & 0.2431 \\
\hline Gender [Boys/Girls] & $26 / 29$ & $17 / 24$ & \\
\hline \multicolumn{4}{|l|}{ Social characteristics } \\
\hline Educational level of father $(\mathrm{N} / \%)$ & & & 0.2081 \\
\hline Without diploma & $9(16.4 \%)$ & 4 (9.8\%) & \\
\hline CAP or BEP & $11(20 \%)$ & 5 (12.2\%) & \\
\hline Baccalaureate & $14(25.5 \%)$ & 19 (46.3\%) & \\
\hline Two years after baccalaureate & $9(16.4 \%)$ & $4(9.8 \%)$ & \\
\hline $\begin{array}{l}\text { Graduate and postgraduate } \\
\text { diplomas }\end{array}$ & $7(12.7 \%)$ & 8 (19.5\%) & \\
\hline Missing & $5(9.1 \%)$ & $1(2.4 \%)$ & \\
\hline Educational level of mother $(\mathrm{N} / \%)$ & & & $0.0212^{\star}$ \\
\hline Without diploma & $9(16.4 \%)$ & $14(34.1 \%)$ & \\
\hline CAP or BEP & $10(18.2 \%)$ & $2(4.9 \%)$ & \\
\hline Baccalaureate & $13(23.6 \%)$ & $12(29.3 \%)$ & \\
\hline Two years after baccalaureate & $15(27.3 \%)$ & $4(9.8 \%)$ & \\
\hline $\begin{array}{l}\text { Graduate and postgraduate } \\
\text { diplomas }\end{array}$ & $6(10.9 \%)$ & $8(19.5 \%)$ & \\
\hline Missing & $2(3.6 \%)$ & $1(2.4 \%)$ & \\
\hline Profession of father & & & 0.7501 \\
\hline Farmers, farm operator & $2(3.6 \%)$ & $3(7.3 \%)$ & \\
\hline $\begin{array}{l}\text { Artisans, traders and } \\
\text { entrepreneurs }\end{array}$ & $4(7.3 \%)$ & $4(9.8 \%)$ & \\
\hline $\begin{array}{l}\text { Employees and higher intellectual } \\
\text { professions }\end{array}$ & $14(25.5 \%)$ & $6(14.6 \%)$ & \\
\hline Employees & $10(18.2 \%)$ & $10(24.4 \%)$ & \\
\hline Worker & $10(18.2 \%)$ & $10(24.4 \%)$ & \\
\hline Intermediate professions & $8(14.5 \%)$ & $4(9.8 \%)$ & \\
\hline Without activity & $3(5.5 \%)$ & $3(7.3 \%)$ & \\
\hline Missing & $4(7.3 \%)$ & $1(2.4 \%)$ & \\
\hline Profession of mother & & & $0.0298^{\star}$ \\
\hline $\begin{array}{l}\text { Employees and higher intellectual } \\
\text { professions }\end{array}$ & $15(27.3 \%)$ & $5(12.2 \%)$ & \\
\hline Employees & $21(38.2 \%)$ & $18(43.9 \%)$ & \\
\hline Worker & $1(1.8 \%)$ & $4(9.8 \%)$ & \\
\hline Intermediate professions & $10(18.2 \%)$ & $2(4.9 \%)$ & \\
\hline Without activity & $8(14.5 \%)$ & $11(26.8 \%)$ & \\
\hline Missing & $0(0 \%)$ & $1(2.4 \%)$ & \\
\hline
\end{tabular}

${ }^{*} p<0.001$.

profession) were also analyzed and were similar across groups concerning father data, but significantly different regarding the mother.

\section{Clinical and Neuropsychological Results, Differences Between Sporadic and Familial Variants}

Numerical variables $(n=49)$ are presented in Table 2. For each variable, mean and standard deviation are displayed as well as the $p$-values of the Student and the Wilcoxon-Mann-Whitney 
TABLE 2 | Clinical Characteristics of the Sporadic and Familial Groups.

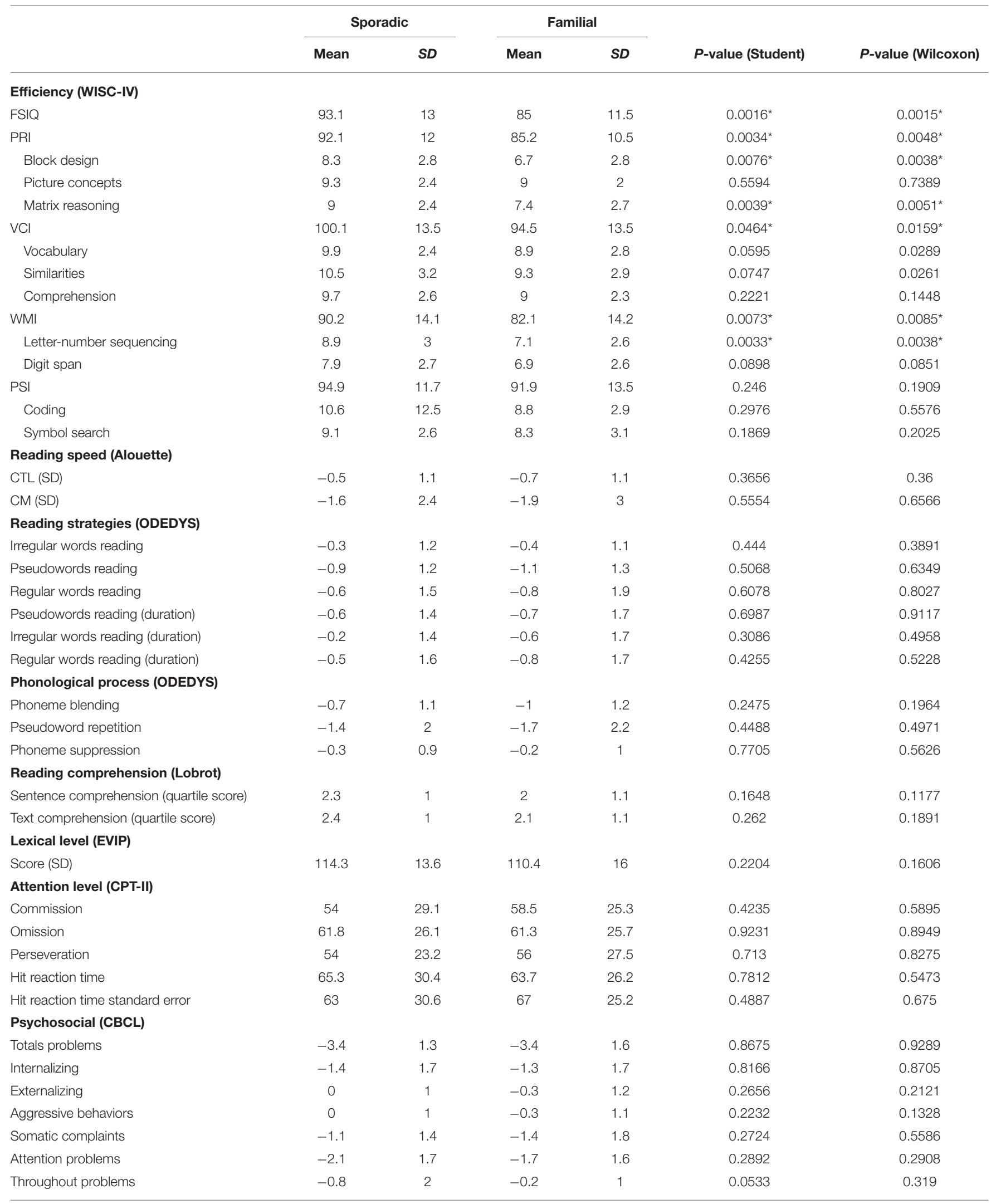

(Continued) 


\begin{tabular}{|c|c|c|c|c|c|c|}
\hline & \multicolumn{2}{|c|}{ Sporadic } & \multicolumn{2}{|c|}{ Familial } & \multirow[b]{2}{*}{$P$-value (Student) } & \multirow[b]{2}{*}{$P$-value (Wilcoxon) } \\
\hline & Mean & $S D$ & Mean & $S D$ & & \\
\hline Social withdrawal & -1 & 1.7 & -0.7 & 1.5 & 0.4654 & 0.3882 \\
\hline Delinquent behaviors & -0.2 & 1.1 & -0.4 & 1.7 & 0.5103 & 0.8937 \\
\hline Social problems & -1.4 & 1.7 & -1.2 & 1.9 & 0.6092 & 0.4508 \\
\hline Anxiety/Depression & -1.2 & 1.6 & -1.1 & 1.6 & 0.6417 & 0.5471 \\
\hline \multicolumn{7}{|c|}{ Visuoperceptual abilities } \\
\hline JLO score & -1 & 1.2 & -1.4 & 1.2 & 0.0964 & 0.0955 \\
\hline Thurstone score & 0 & 0.9 & -0.2 & 0.9 & 0.2048 & 0.2492 \\
\hline Forward span (Corsi) & 0.1 & 1.3 & 0 & 1.4 & 0.6743 & 0.8572 \\
\hline Backward span (Corsi) & 0.5 & 1.2 & 0.5 & 0.9 & 0.7652 & 0.9844 \\
\hline
\end{tabular}

${ }^{*} p<$ 0.001. FSIQ, Full Scale IQ; VCI, Verbal Comprehension Index; PRI, Perceptual Reasoning Index; WMI, Working Memory Index; PSI, Processing Speed Index.

TABLE 3 | $p$-values for individuals effects (NF1 group, level of education mother and father, profession mother and father) from a 5-factor ANOVA performed on each significant numerical variable.

\begin{tabular}{|c|c|c|c|c|c|}
\hline & Transmission & Educational level of mother & Educational level of father & Profession of mother & Profession of father \\
\hline $\mathrm{FSIQ}$ & $0.0003^{*}$ & $0.0135^{\star}$ & 0.1643 & 0.7697 & 0.5235 \\
\hline PRI & $0.0016^{\star}$ & $0.0261^{\star}$ & 0.2156 & 0.4637 & 0.9465 \\
\hline WMI & $0.0044^{\star}$ & 0.711 & 0.3492 & 0.9438 & 0.3373 \\
\hline $\mathrm{VCl}$ & $0.0056^{\star}$ & $0.0778^{\star}$ & 0.6654 & 0.9303 & 0.6537 \\
\hline Matrix reasoning & $0.0028^{*}$ & 0.6458 & 0.8606 & 0.4742 & 0.5788 \\
\hline Block design & $0.0056^{\star}$ & $0.0802^{*}$ & 0.0854 & 0.1498 & 0.6718 \\
\hline Letter-number sequencing & $0.0035^{\star}$ & 0.5546 & 0.4163 & 0.7115 & 0.3456 \\
\hline
\end{tabular}

${ }^{*} p<0.001$.

tests. The variables are ordered depending on the test or cognitive processes evaluated.

The differences between sporadic and familial variants were investigated in three ways.

First, a screening consisted of performing two sample statistical tests (Table 2) which highlights, on the one hand, the consistency of the results between the two tests, and on the other hand, some variables (ordered below depending on the increasing $p$-values of the Student tests) with significant differences between the sporadic and familial variants: FSIQ, Letter-Number Sequencing, Perceptual Reasoning Index, Matrix Reasoning, Working Memory Index, Block Design, and Verbal Comprehension Index obtained an uncorrected $p$-value lower than $5 \%$. As we are in a multiple testing context, adjusted $p$-values with Bonferroni correction were also calculated. This correction resulted in $p$-values systematically higher than $5 \%$. This means that our results have to be considered with moderation and not as highly significant results. But, the fact remains that the lowest $p$-values are associated with the numerical variables showing differences between the two variants.

Secondly, the effect of SES variables together with the NF1 variant was studied in 5-factor ANOVAs. The results are presented in Table 3 for the IQ variables with differences between both groups (with a $p$-value for the NF1 variant factor lower than $5 \%$ in Table 2). It appeared that the numerical variables with the lowest $p$-values for the NF1 variant remained nearly the same as in the first step (FSIQ, PRI, Matrix Reasoning, etc.). In addition, more interestingly, the level of education of the mother was the SES variable with the lowest $p$-value. Let's note also that the Bonferroni correction applied on these $p$-values would give $0.0147\left(0.0003^{*} 49\right)$ for the $p$-value of the NF1 variant related to FSIQ. Thus, the effect of the NF1 variant on the FSIQ is significant when SES is taken into account.

Thirdly, as the level of education of the mother seemed to be the most important SES variable, we focused on the cross-effects of this factor with the NF1 variant. To address this problem, we ran 2-factor ANOVAs with interactions. The results, presented in Table 4, show that the interaction effect is never significant. This means that the effects of NF1 variant and the level of education of the mother occur independently: the effect of one factor does not depend on the level of the other factor.

\section{DISCUSSION}

In the current study, we wanted to elucidate if NF1 transmission has an impact on the wide variability on cognitive phenotype in NF1 children. The only difference from a broad battery of neuropsychological tests -including psychometric, reading (text and word), phonological, visual-spatial, reading comprehension 
TABLE 4 | $p$-values for individual effects (NF1 group, level of education mother) and interaction from a 2-factor ANOVA including interaction performed on each IQ variable.

\begin{tabular}{|c|c|c|c|}
\hline & Transmission & $\begin{array}{c}\text { Educational } \\
\text { level of mother }\end{array}$ & Interaction \\
\hline $\mathrm{FSIQ}$ & $0.0021^{*}$ & $0.015^{\star}$ & 0.6528 \\
\hline PRI & $0.0045^{\star}$ & $0.0227^{\star}$ & 0.3516 \\
\hline Block design & $0.0125^{\star}$ & $0.065^{\star}$ & 0.326 \\
\hline Picture concepts & 0.5473 & $0.046^{\star}$ & 0.1148 \\
\hline Matrix reasoning & $0.0059^{*}$ & 0.6793 & 0.9964 \\
\hline WMI & $0.0133^{\star}$ & 0.6012 & 0.2884 \\
\hline Letter-number sequencing & $0.0073^{\star}$ & 0.8355 & 0.3677 \\
\hline Digit span & 0.138 & 0.7085 & 0.3205 \\
\hline $\mathrm{VCl}$ & $0.0298^{\star}$ & 0.1469 & 0.2034 \\
\hline Comprehension & 0.166 & 0.4325 & 0.0636 \\
\hline Similarities & $0.0403^{\star}$ & $0.0051^{*}$ & 0.2901 \\
\hline Vocabulary & 0.0557 & 0.5358 & 0.715 \\
\hline PSI & 0.2936 & $0.0283^{\star}$ & 0.5703 \\
\hline Symbol search & 0.2027 & 0.1724 & 0.2258 \\
\hline Coding & 0.3785 & 0.4323 & 0.2128 \\
\hline
\end{tabular}

${ }^{\star} p<0.001$.

(sentences and text), receptive language, attention and psychosocial assessments- was in the IQ scores.

\section{IQ Differences Between Sporadic and Familial Form of NF1}

We detected a highly significant difference between sporadic and familial NF1 cases in all index scores -except Processing Speed Index (PSI)-, Full Scale IQ (FSIQ) and three subtests: Matrix Reasoning, Block Design, and Letter-Number Sequencing.

For the FSIQ, PSI, and WMI, children affected by the familial variant of NF1 were lower than average (standard scores around 80 to 85 for indexes and between 6 and 7 for subtests) while children affected by the sporadic variant of NF1 were average (90 to 95 for indexes and around 9 for subtests) suggesting that patients with sporadic NF1 adapt better to the disease than familial cases.

Our results were in accordance to those of Coutinho et al. (90) that have found better scores in FSIQ, VCI and WMI (the details of the subtests has not been carried out) in children with sporadic NF1 than children with familial NF1. However, our results differ from those of Lehtonen et al. (91), Hyman et al. (10), and Ferner et al. (20) who found similar IQ scores between sporadic and familial variants. Several reasons can be put forward to explain such discrepancies in the results. First, these three studies were designed to compare cognitive profiles between NF1 patients and controls and not between the sporadic and familial variants of NF1. Thus, the authors did not specify if both groups were taken from comparable populations (if number, percentage, age, sex, number of borderline IQ is comparable between groups, if the main confounders were identified and taken into account in the design and analyses to minimize the risk of bias, etc.). Secondly, differences can be due to the sample age. In our study, children are between 8 and 12 years old, while in Hyman et al. (10) and Lehtonen et al. (91), children were older ( 8 to 16.75 years and 6 to 16 years, respectively) and in Ferner et al. (20), the 103 patients with NF1 (51 sporadic NF1 cases and 52 familial NF1 cases) are between 6 and 75 years (mean age 27.6 y/o; SD 18.2). Genetic influences-that explain significant parts of the observed variation in cognitive functioning, both for children and adults $(92,93)$ - tend to increase in significance with age, while environmental influences decrease in significance across development (94-96). Brant et al. (94) especially show that the environmental factors that have an influence on variance in intelligence are very minor from age 12 onwards. There is a great similarity of the pattern of contributing factors from between ages 12 and 16, suggesting that the etiology of individual changes in intelligence development is extremely constant by early adolescence. Another and final explanation to such a discrepancy is that, in these three previous studies, mental retardation is not excluded and $6.2 \%$ of children with NF1 in Hyman et al. (10), 6\% in Lehtonen et al. (91) and 8\% in Ferner et al. (20) have an FSIQ $<70$. The inclusion of extreme cognitive profiles is probably a bias (controlled in our study) that leads to different results.

Over the last two decades, there have been a number of studies, summarized in the systematic review of Lehtonen et al. (12), that have studied the general intellectual functioning of children with NF1. The majority of studies have shown that, although children with NF1 have IQs in the normal range, their IQ is often lower (around 90s) than their peers or than their unaffected siblings $(10,19,20,97)$. However, some studies failed to prove differences in IQ between children with NF1 and norms $(29,98-100)$. In addition, Lehtonen et al. (12) pointed out a disagreement to the IQ profile of children with NF1: while some studies demonstrated that children with NF1 scored less on all subtests of the WISC, some others detected some significant differences in only some subtests (Block design or Digit span, for example.) between children with NF1 and their siblings. Difference in proportion of transmission (proportion of sporadic vs. familial NF1 in the final sample) variant could perhaps explain these contradictory results.

We found a difference between sporadic and familial NF1 children regarding Block Design (8.3 vs. 6.7, respectively), Matrix Reasoning (9 vs. 7.4) and Letter-Number Sequencing (8.9 vs. 7.1). Block designed ${ }^{1}$ and Matrix reasoning ${ }^{2}$ (moderately correlate each other; $r=0.55$ ) are known to be a good measure of general and fluid intelligence abilities. They measure non-verbal reasoning, visual processing and abstract, visual perception and organization, visual-spatial ability (and visual-constructional ability for Block Design). Letter-Number Sequencing ${ }^{3}$ measures attention span, short-term auditory memory processing,

\footnotetext{
${ }^{1} \mathrm{BD}$ (core Perceptual Reasoning subtest) require children to put together red-andwhite specially designed blocks in a pattern according to a displayed model. The subtest is timed.

${ }^{2} \mathrm{MR}$ (core Perceptual Reasoning subtest) require children to complete a matrix or serial reasoning problem by selecting a missing picture from five response choices. The subtest is untimed.

${ }^{3}$ LNS (core Working Memory Subtest) require children to repeat in a predetermined order to the examiner a series of numbers and letters that they just heard. The subtest is untimed.
} 
sequential processing and mental manipulation (101-104). Those three subtests may be influenced by concentration and attention.

Differences between sporadic and familial groups of NF1 children in those three subtests are very interesting. All three are considered to be the hallmark phenotypic characteristics of patients with NF1: children with NF1 are known to have serious difficulties in visual-spatial abilities, memory and attention (11, $12,23,25,81,91,105)$.

Altogether, it is therefore legitimate to ask whether IQ difference -largely previously proved between NF1 children and peers or unaffected siblings- persist if the modality of transmission is taken into account. Are differences maintained between children affected by a sporadic variant of NF1 and peers and siblings? Do children with the familial variant of NF1 constitute a "bias" or an explanation to the wide variability in cognitive profile of NF1? More research is needed to detail this specific topic. The mode of transmission of NF1 also seems essential to be taken into account in future studies about the cognitive profile of NF1 subjects.

\section{What Is the Role of Socioeconomic Status (SES) for Such IQ Differences in NF1?}

Today, the concept that the cognitive performance of an individual depends approximately equally on his/her genetic heritage and his/her environment is a consensus. Recent genomewide meta-analyses and research studies have identified genomic loci and genes linked to variation in intelligence (106-111). However, it is also known that the socio-economic background of the child places constraints on their IQ $(95,112)$. First, indices of the families' SES (education, occupation and income of parents) have been proved to moderate the heritability of their children's intelligence (113-115). The heritability of IQ is higher for children who are raised in high SES environments (115). The results of Turkheimer et al. (114) especially demonstrate that the proportion of IQ variance due to environment and genes change non-linearly with SES: in disadvantaged families, the contribution of genes is close to zero and the environment (SES) explains $60 \%$ of the IQ variance, whereas is it the reverse in wealthy families. Secondly, in the general literature, the SES environment has been shown to account for variance in cognitive functioning in childhood in many studies. The effects of the environment on IQ, especially the link between the socioeconomic level of parents (socioeconomic status and parental education) and the cognitive performance of children is therefore well-established $(96,115)$. Of course, the level of education of the child's family environment is involved (especially that of the mother): parents from high SES environments indeed offer more occasions for activities and learning experiences to boost and encourage children's intellectual development (115). But differences in intellectual outcomes could also be attributable to the family income, nutrition, sleep, stress, availability of parents, maternal, and paternal involvement, etc. -that have a direct impact on the child's cognitive development and that is directly connected to the child's environment. For example, concerning income, Noble et al. (116) followed a cohort of 1,099 individuals aged 3 to 20 years. Authors highlighted that income relates most strongly to brain structure (especially in regions supporting language, reading, executive functions and spatial skills) among the most disadvantaged children: small differences in income were associated with large differences in brain surface area in these children, whereas in higher income families, the same differences in income involved smaller differences in surface area). Thirdly, some recent studies tend to highlight the link between IQ and epigenetic mechanisms [temporary (or not) genetic changes supported by environment]. For example, in times of high stress, physiological changes in the organism can modify genes. These modifications can impact a set of features that can have knock-on effects affecting the child development. Kaminski et al. (117) have especially found a relationship between the epigenetic modifications of one specific gene and IQ, indicating experiences have an impact on the genetic mechanisms involved in complex processes such as intelligence. Authors thus show that individual differences in IQ are linked to differences in brain activity and epigenetic changes, which are both under environmental influences.

Altogether, studies have found a strong relationship between IQ and SES in the general population, suggesting our experiences/environment not only affect our quality of life, the wiring of our brain, but the very way our cognitive function evolves.

In the NF1 children population, Hyman, Lehtonen and Ferner's studies have examined predictors of the lowering of general cognitive ability and have only found an association with socioeconomic status. SES has also been found to correlate with general intelligence in Lorenzo et al. $(118,119)$.

In our study, we have found a strong link between (1) sporadic/familial form, (2) IQ and (3) SES family background, especially the mother's education level.

Firstly, children with familial NF1 had a significantly lower SES than children with sporadic NF1, which is consistent with other NF1 studies $(90,91,118)$. Lorenzo et al. (118) especially found in a population of 43 children with NF1 ( 25 sporadic cases and 18 familial cases) that $68 \%$ had mothers who completed a university or postgraduate degree in sporadic cases group compared to $28 \%$ in the familial cases group. Coutinho et al. (90) similarly found lower SES in children with the familial transmission than in children with the sporadic transmission (41\% vs. $19 \%)$. Such distribution does not appear to be an unexpected outcome: the sporadic vs. familial NF1 variant has an impact on the social level in which the child evolves (91, 118). NF1 frequently leads to learning disabilities, poor school academic performances (23), lower education level (less likely to graduate from school, less likely to complete tertiary education), and restrict individuals choice and their professional future (individuals with NF1 are and thus fall into lower socio-economic groups) (120).

Secondly, and as previously shown in the general population $(115,121)$ and in the NF1 population $(10,90,118)$, we found that SES was, in turn, associated with IQ achievement. NF1 children from greater SES backgrounds (here children affected by the sporadic variant) had greater cognition scores than those raised from lower SES backgrounds (here children affected by the 
inherited variant). Our results are in accordance with Lorenzo et al. (118) and Hyman et al. (10). However, both studies have addressed the issue of the relationship between NF1 in its entirety, IQ and SES $(10,118,119)$, without addressing the specific question of the relationship between NF1 variants, IQ and SES. Our results are also in line with Coutinho et al. (90), who found that children with the familial transmission had a lower FSIQ and tended to have a lower SES compared to those with sporadic NF1. However, the authors did not discuss this association (Cause and effect? Consequence? etc.). Our findings therefore increase those of these four previous studies in the comprehension of this trend, highlighting that the disparity recognized between the sporadic and familial variants is likely due to the impact that the NF1 transmission modality has on the SES environment of the family.

In addition, we also demonstrated that there is no significant interaction between group (transmission forms: sporadic vs. familial) and the relationship between the mother's education level and the IQ of the children. In other words, the mother's education level has an impact on the IQ of the NF1 child, irrespective of the transmission mode (sporadic or familial). Having a low SES has a snowball effect on other variables -as cognitive variables- but effect is irrespective of inherited variant. However, as familial NF1 leads more frequently to a low SES, familial NF1 children are most often affected.

\section{Toward a More Complex and Multi-Factorial Approach to Explaining Specific Cognitive Phenotypes in NF1}

Another important finding is the absence of differences for tests exploring the usually affected cognitive domains in NF1 (language, visual-spatial domain, executive functions, attention) between the two forms of NF1. We indeed used 10 tests leading to 49 measures, completed by four SES measures. We only found a single test and only seven measures out of 49 where there is a difference between the sporadic and familial NF1 variants. The majority of cognitive functions are therefore not different between the two groups. Consequently, we can argue that transmission (sporadic vs. familial) alone failed to explain the wide variability in phenotype NF1 expression.

Our results were consistent with those of Coutinho et al. (90). Although authors found that children with sporadic NF1 performed better than those with familial NF1 in a large battery of neuropsychological tests (Reading Comprehension tasks, Rey Complex Figure Copy, Spatial Memory, JLO, Imitation of Hand Positions), differences were canceled when FSIQ and SES were taken into account (except for JLO). Our results were also consistent with those of Lehtonen et al. (91) and Erdogan-Bakar et al. (122) where the heritability status of NF1 did not lead to any differences in the performance of the children with NF1 (sporadic vs. familial NF1 groups) on any of the measures (visual-spatial, working memory, spatial memory, executive function, attention, etc.). Note, however, that these two studies were not designed to observe this effect (this is here an ancillary result), so the groups were not controlled and adjusted in terms of number, age, sex, IQ, SES, etc. Our results therefore reinforce, confirm and extend these previous ones with equivalent groups (no bias), and a study especially designed to reply to this question.

The causes of NF1 cognitive phenotype and its variability have been explored with genetic, brain imaging or histological studies (27) but none have successfully explained them until now [for e.g., $(10,18,21,27)]$. Snippets of explanation are sometimes pointed (UBOs, visual-spatial abilities, etc.) but findings are inconsistent across studies. The IQ variability could be explained by the transmission (sporadic vs. familial) and SES status, while another variability typology (motor impairment, social deficit, executive function impairment, etc.) could be explained by another cause. It is therefore possible that the wide variability in NF1 can be explained by a multitude of causes and not just one, which would partly explain why studies fail to explain phenotype variability in NF1 when they address this question from just one perspective.

Overall, cause-and-effect relationships to explain phenotype variability in NF1 are not always easy to establish and more global approaches are probably needed. Multi-causality is also a possible explanation that should be investigated: either as interrelated causes that interact in a particular order to produce the effect; or as the interaction of multiple risk factors, including environmental, economic, lifestyle and genetic predisposition factors.

\section{CONCLUSION}

Altogether, we therefore highlighted (1) that there is an IQ difference between children affected by the sporadic variant compared to the familial variant, (2) that such difference is linked to SES status of the child family, (3) that there is no difference between groups on the impact of SES on IQ, (4) but that there is significantly lower SES in familial NF1 families than in sporadic NF1 families, and (5) that IQ differences between groups seems consequently in part linked to the environment where the child grows up.

The question of NF1 transmission institutes a robust framework to study the impact of environmental determinants and their repercussions on health, care, disease development and prognostics. Inequalities in health reflect the inequalities that can generally be seen within a society. The findings from our study have clinical implications with regard to the management of NF1: children with NF1, and especially those that have early diagnoses (most often in inherited cases), must obtain careful monitoring from their early childhood, at home to strengthen investment in education and in school to early detect emerging academic problems and to quickly place them into care. Our findings also have implications in research that leads to taking care of the effects of inherited and sporadic cases of NF1 in the evaluation of cognitive and behavioral assessments, considering this variable with great interest in developmental studies since it is largely determined by the environment in which the child grows up.

On the other hand, our results imply that the inherited variant of NF1 (familial vs. sporadic) does not explain specific deficits in NF1 (reading, visual-spatial, attention, psychosocial functions). We would strongly encourage research to advance further in 
the understanding of phenotypic variability in NF1, since this is a major hindrance to the prognosis, monitoring, and care of such patients. However, we believe that researching a unique and common cause to the set of variabilities is not the right solution. This variability exerts on many components (presence or not of physical characteristics, cognitive functions impairments, level of the symptoms, which one and which intensity, presence or not of UBOs, their location, their numbers, etc.) and maybe there is one cause behind each type of component or clusters of components. Appropriately identifying the responsibilities behind each variability has a real and significant interest for health care in NF1.

\section{LIMITATION}

Further research on larger NF1 populations is needed, and shall include genetic data recovery to allow genotype-phenotype analyses and their correlation to the neurobehavioral phenotype.

\section{DATA AVAILABILITY STATEMENT}

The datasets generated and/or analyzed during the current study are not publicly available due to the nature of the data (interventional research protocol involving the human person) but are available from the corresponding author on reasonable request.

\section{ETHICS STATEMENT}

This study is registered with ClinicalTrials.gov number NCT02397967. The study was approved by the local ethics committee (CPP Sud-Ouest Outre-Mer 1) and conducted in accordance with the Declaration of Helsinki. Written informed consent to participate in this study was provided by the participants' legal guardian/next of kin.

\section{REFERENCES}

1. Ferner RE, Huson SM, Thomas N, Moss C, Willshaw H, Evans $\mathrm{GD}$, et al. Guidelines for the diagnosis and management of individuals with neurofibromatosis 1. J Med Genet. (2007) 44:81-8. doi: 10.1136/jmg.2006.045906

2. Friedman JM, Birch PH. Type 1 neurofibromatosis: a descriptive analysis of the disorder in 1728 patients. Am J Med Genet. (1997) 70:138-43.

3. Theos A, Korf BR, American College of Physicians, American Physiological Society. Pathophysiology of neurofibromatosis type 1. Ann Intern Med. (2006) 144:842-9. doi: 10.7326/0003-4819-144-11-200606060-00010

4. Sabol Z, Rešić B, Gjergja Juraški R, Sabol F, Kovač ŠiŽgorić M, Oršolić K, et al. Clinical sensitivity and specificity of multiple T2-hyperintensities on brain magnetic resonance imaging in diagnosis of neurofibromatosis type 1 in children: diagnostic accuracy study. Croatian Med J. (2011) 52:48896. doi: $10.3325 / \mathrm{cmj} .2011 .52 .488$

5. Payne JM, Moharir MD, Webster R, North KN. Brain structure and function in neurofibromatosis type 1: current concepts and future directions. J Neurol Neurosurg Psychiatry. (2010) 81:304-9. doi: 10.1136/jnnp.2009.179630

6. Brems H, Beert E, de Ravel, T Legius E. Mechanisms in the pathogenesis of malignant tumours in neurofibromatosis type 1. Lancet Oncol. (2009) 10:508-15. doi: 10.1016/S1470-2045(09)70033-6

\section{AUTHOR CONTRIBUTIONS}

YC is the principal investigator of the study, conceived the idea for the study, and was a major contributor in writing the protocol. YC, MB, and EB analyzed and interpreted the data, conceived the first working plan based on results, and wrote the manuscript. SD carried out the statistical analysis, wrote the statistical sections of the manuscript, and reviewed the final manuscript. SL was involved in study coordination and quality monitoring. NF-M was involved in study coordination and carried out the neuropsychological tests. SI carried out the neuropsychological tests. PC and FR included patients. VL-C contributed to the writing of the protocol and reviewed the final manuscript. All the authors read and approved the final manuscript as submitted and agreed to be accountable for all aspects of the work.

\section{FUNDING}

This work was supported by a grant from the Clinical Research Hospital Programme from the French Ministry of Health (PHRC 2008, Toulouse University Hospital, No. 08113 01) and a grant from the Occitanie Region (APRTC No. 09004813).

\section{ACKNOWLEDGMENTS}

This work is dedicated to the children and their families who participated in the study. We would like to thank the NF network France, the ANR France association and the Occitanie Region for their support. The authors also thank Elisabeth Schweitzer, Diana Rodriguez, Isabelle Kemlin, Nathalie Dorison, Maryline Carneiro, Elodie Preclaire, Sebastien Barbarot for their help, and Jérome Huart for the English language editing.

7. Friedman JM. Epidemiology of neurofibromatosis type 1. Am J Med Genet. (1999) 89:1-6.

8. Williams VC, Lucas J, Babcock MA, Gutmann DH, Korf B, Maria BL. Neurofibromatosis Type 1 Revisited. Pediatrics. (2009) 123:12433. doi: 10.1542/peds.2007-3204

9. de Bella K, Szudek J, Friedman JM. Use of the national institutes of health criteria for diagnosis of neurofibromatosis 1 in children. Pediatrics. (2000) 105:608-14. doi: 10.1542/peds.105.3.608

10. Hyman SL, Shores EA, North KN. The nature and frequency of cognitive deficits in children with neurofibromatosis type 1. Neurology. (2005) 65:1037-44. doi: 10.1212/01.wnl.0000179303.72345.ce

11. Hachon C, Iannuzzi S, Chaix Y. Behavioural and cognitive phenotypes in children with Neurofibromatosis type 1 (NF1): the link with the neurobiological level. Brain Dev. (2011) 33:52-61. doi: 10.1016/j.braindev.2009.12.008

12. Lehtonen A, Howie E, Trump D, Huson SM. Behaviour in children with neuro fibromatosis type 1: cognition, executive function, attention, emotion, and social competence. Dev Med Child Neurol. (2013) 55:11125. doi: 10.1111/j.1469-8749.2012.04399.x

13. Levine TM, Materek A, Abel J, O'Donnell M, Cutting LE. Cognitive profile of neurofibromatosis type 1. Semin Pediatr Neurol. (2006) 13:8-20. doi: 10.1016/j.spen.2006.01.006 
14. North K, Hyman S, Barton B. Cognitive deficits in neurofibromatosis 1. J Child Neurol. (2002) 17:605-12. doi: 10.1177/088307380201700811

15. Kayl AE, Moore III BD, Slopis JM. Quantitative morphometry of the corpus callosum in children with neurofibromatosis and attention-deficit hyperactive disorder. J Child Neurol. (2000) 15:90-6. doi: 10.1177/088307380001500206

16. Acosta MT, Gioia GA, Silva AJ. Neurofibromatosis type 1: new insights into neurocognitive issues. Curr Neurol Neurosci Rep. (2006) 6:13643. doi: 10.1007/s11910-996-0036-5

17. Cutting LE, Clements AM, Lightman AD, Yerby-Hammack PD, Denckla MB. Cognitive profile of neurofibromatosis type 1: rethinking nonverbal learning disabilities. Learn Disabil Res Pract. (2004) 19:155-65. doi: 10.1111/j.1540-5826.2004.00099.x

18. Hyman SL, Shores EA, North KN. Learning disabilities in children with neurofibromatosis type 1: subtypes, cognitive profile, and attention deficit-hyperactivity disorder. Dev Med Child Neurol. (2006) 48:9737. doi: 10.1111/j.1469-8749.2006.tb01268.x

19. North K, Riccardi V, Samango-Sprouse C, Ferner R, Moore B, Legius E, et al. Cognitive function and academic performance in neurofibromatosis 1 : consensus statement from the NF1 cognitive disorders task force. Neurology. (1997) 48:1121-7. doi: 10.1212/WNL.48.4.1121

20. Ferner RE, Hughes RA, Weinman J. Intellectual impairment in neurofibromatosis 1. J Neurol Sci. (1996) 138:12533. doi: 10.1016/0022-510X(96)00022-6

21. Hyman SL, Gill DS, Shores EA, Steinberg A, Joy P, Gibikote SV, et al. Natural history of cognitive deficits and their relationship to MRI T2-hyperintensities in NF1. Neurology. (2003) 60:1139-45. doi: 10.1212/01.WNL.0000055090.78351.C1

22. Schrimsher GW, Billingsley RL, Slopis JM, Moore BD III. Visual-spatial performance deficits in children with neurofibromatosis type-1. Am J Med Genet. (2003) 120A:326-30. doi: 10.1002/ajmg.a.20048

23. Descheemaeker MJ, Ghesquière P, Symons H, Fryns JP, Legius E. Behavioral, academic and neuropsychological profile of normally gifted Neurofibromatosis type 1 children. I Intellect Disabil Res. (2005) 49:3346. doi: 10.1111/j.1365-2788.2005.00660.x

24. Payne JM, Hyman SL, Shores EA, North KN. Assessment of executive function and attention in children with neurofibromatosis type 1 : relationships between cognitive measures and real-world behavior. Child Neuropsychol. (2011) 17:313-29. doi: 10.1080/09297049.2010.542746

25. Torres Nupan MM, Velez Van Meerbeke A, López Cabra CA, Herrera Gomez PM. Cognitive and behavioral disorders in children with neurofibromatosis type 1. Front. Pediatr. (2017) 5:227. doi: 10.3389/fped.2017.00227

26. Gilboa Y, Rosenblum S, Fattal-Albert A, Toledano-Alhadef H, Rizzo A., Josman N. Using a virtual classroom environment to describe the attention deficits profile of children with Neurofibromatosis type 1. Res Dev Disabil. (2011) 32:2608-613. doi: 10.1016/j.ridd.2011.06.014

27. Baudou E, Nemmi F, Biotteau M, Maziero S, Peran P, Chaix Y. Can the cognitive phenotype in Neurofibromatosis type 1 (NF1) be explained by neuroimaging? A review. Front Neurol. (2019) 10:1373. doi: 10.3389/fneur.2019.01373

28. Di Paolo DP, Zimmerman RA, Rorke LB, Zackai EH, Bilniuk LH, Yachmis AT. Neurofibromatosis type 1: pathologic substrate of high signal intensity foci in the brain. Neuroradiology. (1995) 195:7214. doi: 10.1148/radiology.195.3.7754001

29. Moore BD, Slopis JM, Schomer D, Jackson EF, Levy BM. Neuropsychological significance areas of high signal intensity on brain MRIs of children with neurofibromatosis. Neurology. (1996) 46:1660-8. doi: 10.1212/WNL.46.6.1660

30. Piscitelli O, Digilio MC, Capolino R, Longo D, Di Ciommo V. Neurofibromatosis type 1 and cerebellar T2-hyperintensities: the relationship to cognitive functioning. Dev Med Child Neurol. (2012) 54:49-51. doi: 10.1111/j.1469-8749.2011.04139.x

31. Feldmann R, Schuierer G, Wessel A, Neveling N, Weglage J. Development of MRI T2 hyperintensities and cognitive functioning in patients with neurofibromatosis type 1. Acta Paediatr. (2010) 99:1657-60. doi: 10.1111/j.1651-2227.2010.01923.x
32. Noll RB, Reiter-Purtill J, Moore BD, Schorry EK, Lovell AM, Vannatta K, et al. Social, emotional, and behavioral functioning of children with NF1. Am J Med Gene A. (2007) 143:2261-73. doi: 10.1002/ajmg.a.31923

33. Graf A, Landolt MA, Capone Mori A., Boltshauser E. Quality of life and psychological adjustment in children with neurofibromatosis type $1 . J$ Pediatrics. (2006) 149:348-53. doi: 10.1016/j.jpeds.2006.04.025

34. Page PZ, Page GP, Ecosse E, Korf BR, Leplege A, Wolkenstein P. Impact of Neurofibromatosis 1 on quality of life: a cross-sectional study of 176 American cases. Am J Med Gene A. (2006) 140:18938. doi: 10.1002/ajmg.a.31422

35. Oostenbrink R, Spong K, De Goede-Bolder A, Landgraf JM, Raat H, Moll HA. Parental reports of health-related quality of life in young children with Neurofibromatosis type 1: influence of condition specific determinants. $J$ Pediatr. (2007) 151:182-6. doi: 10.1016/j.jpeds.2007.03.005

36. Wolkenstein P, Rodriguez D, Ferkal S, Gravier H, Buret V, Algans N, et al. Impact of Neurofibromatosis 1 upon quality of life in childhood: a cross-sectional study of 79 cases. Br J Dermatol. (2009) 160:8448. doi: 10.1111/j.1365-2133.2008.08949.x

37. Krab LC, Aarsen FK, de Goede-Bolder A, Catsman-Berrevoets, Arts WF, Moll WF, et al. Impact of neurofibromatosis type 1 on school performance. $J$ Child Neurol. (2008) 23:1002-10. doi: 10.1177/0883073808316366

38. Coudé FX, Mignot C, Lyonnet S, Munnich A. Academic impairment is the most frequent complication of Neurofibromatosis type-1 (NF1) in children. Behav Genet. (2006) 36:660-4. doi: 10.1007/s10519-005-9040-9

39. Neurofibromatosis. Conference statement. National Institutes of Health Consensus Development Conference. Arch Neurol. (1988) 45:575-78. doi: 10.1001/archneur.1988.00520290115023

40. Boyd KP, Korf BR, Theos A. Neurofibromatosis type 1. J Am Acad Dermatol. (2009) 61:1-14. doi: 10.1016/j.jaad.2008.12.051

41. Tonsgard JH. Clinical manifestations and management of neurofibromatosis type 1. Pediatr Neurol. (2006) 13:2-7. doi: 10.1016/j.spen.2006.01.005

42. Evans DG, Howard E, Giblin C, Clancy T, Spencer H, Huson SM, et al. Birth incidence and prevalence of tumour prone syndromes: estimates from a UK genetic family register service. Am J Med Genet A. (2010) 152:32732. doi: 10.1002/ajmg.a.33139

43. Rasmussen SA, Friedman JM. NF1 gene and neurofibromatosis 1. Am J Epidemiol. (2000) 151:33-40. doi: 10.1093/oxfordjournals.aje.a010118

44. Side LE, Shannon KM. The NF1 gene as a tumour suppressor. In: Upadhyaya M, Cooper DN editors. Neurofibromatosis Type 1: From Genotype to Phenotype. Oxford: BIOS Scientific (1998). p. 133-51.

45. Viskochil D, Buchberg AM, Xu G, Cawthon RM, Stevens J, Wolff RK, et al. Deletions and a translocation interrupt a cloned geneat the neurofi bromatosis type 1 locus. Cell. (1990) 62:187-92. doi: 10.1016/0092-8674(90)90252-A

46. Wallace MR, Andersen LB, Saulino AM, Gregory PE, Glover TW, Collins FS. A de novo Alu insertion results in neurofibromatosis type 1. Nature. (1991) 353:864-6. doi: 10.1038/353864a0

47. Daston MM, Scrable H, Nordlund M, Sturbaum AK, Nissen LM, Ratner $\mathrm{N}$. The protein product of the neurofibromatosis type 1 gene is expressed at highest abundance in neurons, Schwann cells, and oligodendrocytes. Neuron. (1992) 8:415-28. doi: 10.1016/0896-6273(92)90270-N

48. Johannessen CM, Reczek EE, James, MF, Brems H, Legius E, Cichowski K. The NF1 tumour suppressor critically regulates TSC2 and mTOR. Proc Natl Acad Sci USA. (2005) 102:8573-78. doi: 10.1073/pnas.0503224102

49. Lee MJ, Stephenson DA. Recent developments in neurofibromatosis type 1. Curr Opin Neurol. (2007) 20:135-41. doi: 10.1097/WCO.0b013e3280895da8

50. Upadhyaya M, Kluwe L, Spurlock G, Monem B, Majounie E, Mantripragada $\mathrm{K}$, et al. Germline and somatic NF1 gene mutation spectrum in NF1associated malignant peripheral nerve sheath tumors (MPNSTs). Hum Mutat. (2008) 29:74-82. doi: 10.1002/humu.20601

51. Huson SM, Compston DA, Clark P, Harper PS. A genetic study of von Recklinghausen neurofibromatosis in South East Wales. Prevalence I, fitness, mutation rate, and effect of parental transmission on severity. J Med Genet. (1989) 26:704-11. doi: 10.1136/jmg.26.11.704

52. Riccardi VM. Neurofibromatosis: Phenotype, Natural History, and Pathogenesis, 2nd ed. Baltimore, MD: The Johns Hopkins University Press (1992). 
53. Vogel F, Motulsky AG. Human Genetics: Problems and Approaches, 3rd ed. Berlin: Springer-Verlag (1997).

54. Xu GF, O'Connell P, Viskochil D, Cawthon R, Robertson M, Culver M, et al. The Neurofibromatosis type 1 gene encodes a protein related to GAP. Cell. (1990) 62:599-608. doi: 10.1016/0092-8674(90)90024-9

55. Cichowski K, Jacks T. NF1 tumor suppressor gene function: narrowing the GAP. Cell. (2001) 104:593-604. doi: 10.1016/S0092-8674(01)00245-8

56. Upadhyaya M, Cooper DN. The mutational spectrum in neurofibromatosis type 1 and its underlying mechanisms. In: Upadhyaya M, Cooper DN, editors. Neurofibromatosis Type 1: From Genotype to Phenotype. Oxford: BIOS Scientific (1998). p. 65-82.

57. Klose A, Peters H, Hoffmeyer S, Buske A, Lüder A, Hess D, et al. Two independent mutations in a family with neurofibromatosis type 1 (NF1). Am J Med Genet. (1999) 83:6-12.

58. Upadhyaya M, Majounie E, Thompson P, Han S, Consoli C, Krawczak $\mathrm{M}$, et al. Three different pathological lesions in the NF1 gene originating de novo in a family with neurofibromatosis type 1. Hum Genet. (2003) 112:12-17. doi: 10.1007/s00439-002-0840-1

59. Kehrer-Sawatzki H, Cooper DN. Mosaicism in sporadic neurofibromatosis type 1: variations on a theme common to other hereditary cancer syndromes? J Med Genet. (2008) 45:622-31. doi: 10.1136/jmg.2008.059329

60. Bottillo I, Torrente I, Lanari V, Pinna V, Giustini S, Divona L, et al. Germline mosaicism in neurofibromatosis type 1 due to a paternally derived multi-exon deletion. Am J Med Genet A. (2010) 152A:146773. doi: 10.1002/ajmg.a.33386

61. Messiaen L, Vogt J, Bengesser K, Fu C, Mikhail F, Serra E, et al. Mosaic type-1 NF1 microdeletions as a cause of both generalized and segmental Neurofibromatosis type-1 (NF1). Hum Mutat. (2011) 32:2139. doi: 10.1002/humu.21418

62. Detjen AK, Tinschert S, Kaufmann D, Algermissen B, Nurnberg P, Schuelke M. Analysis of mitochondrial DNA in discordant monozygotic twins with neurofibromatosis type 1. Twin Res Hum Genet. (2007) 10:48695. doi: 10.1375/twin.10.3.486

63. Kaplan L, Foster R, Shen Y, Parry DM, McMaster ML, O'Leary MC, et al. Monozygotic twins discordant for neurofibromatosis 1. Am J Med Genet A. (2010) 152A:601-6. doi: 10.1002/ajmg.a.33271

64. Crow JF. The origins, patterns and implications of human spontaneous mutation. Nat Rev Genet. (2000) 1:40-7. doi: 10.1038/35049558

65. Liu Q, Zoellner N, Gutmann DH, Johnson KJ. Parental age and neurofibromatosis type 1: a report from the NF1 patient registry initiative. Familial Cancer. (2015) 14:317-24. doi: 10.1007/s10689-014-9774-8

66. Dubov T, Toledano-Alhadef H, Bokstein F, Constantini S, Ben-Shachar S. The effect of parental age on the presence of de novo mutations - lessons from neurofibromatosis type I. Mol Gene Genomic Med. (2016) 4:4806. doi: $10.1002 / \mathrm{mgg} 3.222$

67. Snajderova M, Riccardi VM, Petrak B, Zemkova D, Zapletalova J, Mardesic $\mathrm{T}$, et al. The importance of advanced parental age in the origin of neurofibromatosis type 1. Am J Med Gene A. (2012) 158A:51923. doi: 10.1002/ajmg.a.34413

68. Sharafi P, Ayter S. Possible modifier genes in the variation of neurofibromatosis type 1 clinical phenotypes. J Neurogene. (2018) 32:65-77. doi: 10.1080/01677063.2018.1456538

69. Jadayel D, Fain P, Upadhyaya M, Ponder MA, Huson SM, Carey J, et al. Paternal origin of new mutations in von recklinghausen neurofibromatosis. Nature. (1990) 343:558-59. doi: 10.1038/343558a0

70. Bauer M, Lubs H, Lubs ML. Variable expressivity of neurofibromatosis-1 in identical twins. Neurofibromatosis. (1988) 1:323-9.

71. Easton DF, Ponder MA, Huson SM, Ponder BA. An analysis of variation in expression of Neurofibromatosis (NF) type 1 (NF1): evidence for modifying genes. Am J Hum Gene. (1993) 53:305-13.

72. Koul RL, Chacko A, Leven HO. Dandy-Walker syndrome in association with neurofibromatosis in monozygotic twins. Saudi Med J. (2000) 21:390-92.

73. Roubertoux PL, Sluyter F, Carlier M, Marcet B, Maarouf-Veray F, Cherif $\mathrm{C}$, et al. Mitochondrial DNA modifies cognition in interaction with the nuclear genome and age in mice. Nat Gene. (2003) 35:65-9. doi: 10.1038/ ng1230

74. Sites ER, Smolarek TA, Martin LJ, Viskochil DH, Stevenson DA, Ullrich NJ, et al. Analysis of copy number variants in 11 pairs of monozygotic twins with neurofibromatosis type 1. Am J Med Genet A. (2017) 173A:64753. doi: 10.1002/ajmg.a.38058

75. Diggs-Andrews KA, Brown JA, Gianino SM, Rubin JB, Wozniak DF, Gutmann DH. Sex is a major determinant of neuronal dysfunction in neurofibromatosis type 1. Ann Neurol. (2014) 75:309-16. doi: 10.1002/ana.24093

76. Upadhyaya M, Ruggieri M, Maynard J, Osborn M, Hartog C, Mudd S, et al. Gross deletions of the neurofibromatosis type I (NF1) gene are predominantly of maternal origin and commonly associated with a learning disability, dysmorphic features and developmental delay. Hum Genet. (1998) 102:591-7. doi: 10.1007/s004390050746

77. Szudek J. Growth in North American white children with neurofibromatosis 1 (NF1). J Med Gene. (2000) 37:933-8. doi: 10.1136/jmg.37.12.933

78. Tubridy N, Schon F, Moss A, Clarke A, Cox T, Ferner R. Hippocampal involvement in identical twins with Neurofibromatosis type 1. J Neurol Neurosurg Psychiatry. (2001) 71:131-2. doi: 10.1136/jnnp.71.1.131

79. Pasmant E, Vidaud M, Vidaud D, Wolkenstein P. Neurofibromatosis type 1: from genotype to phenotype. J Med Genet. (2012) 49:4839. doi: 10.1136/jmedgenet-2012-100978

80. Roth TM, Petty EM, Barald KF. The role of steroid www. impactjournals.com/oncotarget 5885 Oncotarget hormones in the NF1 phenotype: focus on pregnancy. Am J Med Genet A. (2008) 146A:1624-33. doi: 10.1002/ajmg.a.32301

81. Chaix Y, Lauwers-Cancès V, Faure-Marie N, Gentil C, Lelong S, Schweitzer E, et al. Deficit in phonological processes: a characteristic of the neuropsychological profile of children with NF1. Child Neuropsychol. (2017) 24:558-74. doi: 10.1080/09297049.2017.1313970

82. Wechsler D. Echelle D'intelligence de Wechsler Pour Enfants et Adolescents, 4th éd. Paris: ECPA (2005).

83. Dunn LM, Theriault-Whalen CM. Dunn LM. Echelle de Vocabulaire en Images Peabody. Adaptation Française du Peabody Picture Vocabulary Test - Revised. Toronto, ON: Pearson (1993).

84. Lefavrais P. Test D'Analyse de la Lecture et de la Dyslexie (Alouette-R). Paris: ECPA (2005).

85. Jacquier-Roux M, Valdois S, Zorman M, Lequette C, Pouget G. Odédys, Outil de Dépistage des Dyslexies. Version 2. Grenoble: Laboratoire Cogni-sciences. (2005).

86. Lobrot M. Lire, Épreuves pour Évaluer la Capacité de Lecture et le Niveau D'orthographe. Paris: ESF (1973).

87. Lindgren SD, Benton AL. Developmental patterns of visuospatial judgment. J Pediatr Psychol. (1980) 5:217-25. doi: 10.1093/jpepsy/5.2.217

88. Conners CK, Staff MHS (editors.). Conners' Continuous Performance Test II: Computer Program for Windows Technical Guide and Software Manual. North Tonwanda, NY: Mutli-Health Systems (2000).

89. Achenbach TM, Rescorla L. The Manual for the ASEBA Scholl-Age Forms Profiles: An Integrated System of Multi-informant Assessment. Burlington, VT: University of Vermont, Research Center for Children, Youth, Families (2001). Adaptation Française : Capron C. Université de Montpellier.

90. Coutinho V, Kemlin I, Dorison N, Billette de Villemeur T, Rodriguez D, Dellatolas G. Neuropsychological evaluation and parental assessment of behavioral and motor difficulties in children with neurofibromatosis type 1 . Res Dev Disabil. (2016) 48:220-30. doi: 10.1016/j.ridd.2015.11.010

91. Lehtonen A, Garg S, Roberts SA, Trump D, Evans DG, Green J. Cognition in children with neurofibromatosis type 1: data from a population-based study. Dev Med Child Neurol. (2015) 57:645-51. doi: 10.1111/dmcn.12734

92. Rijsdijk FV, Vernon PA, Boomsma DI. Application of hierarchical genetic models to Raven and WAIS subtests: a Dutch twin study. Behav Gene. (2002) 32:199-210. doi: 10.1023/A:1016021128949

93. Posthuma D, de Geus EJC, Baaré WFC, Hulshoff HE, Kahn RS, Boomsma DI. The association between brain volume and intelligence is of genetic origin. Nat. Neurosci. (2002) 5:83-4 doi: 10.1038/nn0202-83

94. Brant AM, Haberstick BC, Corley RP, Wadsworth SJ, DeFries JC, Hewitt JK. The developmental etiology of high IQ. Behav Gene. (2009) 39:393405. doi: 10.1007/s10519-009-9268-x

95. Tucker-Drob EM, Briley DA. Continuity of genetic and environmental influences on cognition across the life span: a meta-analysis of longitudinal twin and adoption studies. Psychol Bull. (2014) 140:949-79. doi: 10.1037/a0035893 
96. von Stumm S, Plomin R. Socioeconomic status and the growth of intelligence from infancy through adolescence. Intelligence. (2015) 48:306. doi: 10.1016/j.intell.2014.10.002

97. Cutting LE, Koth CW, Denckla MB. How children with neurofibromatosis type 1 differ from "typical" learning disabled clinic attenders: nonverbal learning disabilities revisited. Dev Neuropsychol. (2000) 17:29-47. doi: 10.1207/S15326942DN1701_02

98. Billingsley RL, Slopis JM, Swank PR, Jackson EF, Moore III BD. Cortical morphology associated with language function in neurofibromatosis, type I. Brain Lang. (2003) 85:125-39. doi: 10.1016/S0093-934X(02)00563-1

99. Dilts CV, Carey JC, Kircher JC, Hoffman RO, Creel D, Ward K, et al. Children and adolescents with neurofibromatosis 1: a behavioural phenotype. J Dev Behav Pediatr. (1996) 17:229-39. doi: 10.1097/00004703-199608000-00004

100. Hofman KJ, Harris EL, Bryan RN, Denckla MB. Neurofibromatosis type 1: the cognitive phenotype. J Pediatr. (1994) 124:S18. doi: 10.1016/S0022-3476(05)83163-4

101. Kaufman AS, Lichtenberger EO. Assessing Adolescent and Adult Intelligence, 3rd ed. Hoboken, NJ: John Wiley Sons (2006).

102. Groth-Marnat G. Handbook of Psychological Assessment, 5th ed. Hoboken, NJ: John Wiley Sons Inc. (2009).

103. Lichtenberger EO, Kaufman AS. Essentials of WAIS-IV Assessment. New York, NY: Wiley (2009).

104. Sattler JM, Ryan JJ. Assessment With the WAIS-I. San Diego, CA: Jerome Sattler M, Publisher, Inc. (2009).

105. Isenberg JC, Templer A, Gao F, Titus JB, Gutmann DH. Attention skills in children with neurofibromatosis type 1. J Child Neurol. (2013) 28:459. doi: 10.1177/0883073812439435

106. Davies G, Armstrong N, Bis JC, Bressler J, Chouraki V, Giddaluru S, et al. Genetic contributions to variation in general cognitive function: a metaanalysis of genome-wide association studies in the CHARGE consortium (N = 53949). Mol. Psychiatry. (2015) 20:183-92. doi: 10.1038/mp.2014.188

107. Davies G, Armstrong N, Bressler J, Chouraki V, Giddaluru S, Hofer E, et al. Genome-wide association study of cognitive functions and educational attainment in UK Biobank $(\mathrm{N}=112$ 151). Mol. Psychiatry. (2015) 21:75867. doi: $10.1038 / \mathrm{mp} .2016 .45$

108. Sniekers S, Stringer S, Watanabe K, Jansen PR, Colema JRI, Krapohl E, et al. Genome-wide association meta-analysis of 78,308 individuals identifies new loci and genes influencing human intelligence. Nat. Genet. (2017) 49:1107-12. doi: 10.1038/ng.3869

109. Trampush JW, Yang ML, Yu J, Knowles E, Davies G, Liewald DC, et al. GWAS meta-analysis reveals novel loci and genetic correlates for general cognitive function: a report from the COGENT consortium. Mol. Psychiatry. (2017) 22:336-45. doi: 10.1038/mp.2016.244

110. Zabaneh D, Krapohl E, Gaspar H, Curtis C, Lee SH, Patel H, et al. A genomewide association study for extremely high intelligence. Mol. Psychiatry. (2018) 23:1226-32. doi: 10.1038/mp.2017.121

111. Savage JE, Jansen PR, Stringer S, Watanabe K, Bryois J, de Leeuw CA, et al. Genome-wide association meta-analysis in 269,867 individuals identifies new genetic and functional links to intelligence. Nat Gene. (2018) 50:912-9. doi: 10.1038/s41588-018-0152-6
112. McLoyd VC. Socioeconomic disadvantage and child development. Am J Psychol. (1998) 53:185-204. doi: 10.1037/0003-066X. 53.2.185

113. Tucker-Drob EM, Rhemtulla M, Harden KP, Turkheimer E, Fask D. Emergence of a Gene x socioeconomic status interaction on infant mental ability between 10 months and 2 years. Psychol Sci. (2011) 22:12533. doi: $10.1177 / 0956797610392926$

114. Turkheimer E, Haley A, Waldron M, D’Onofrio B, Gottesman II. Socioeconomic status modifies heritability of IQ in young children. Psychol Sci. (2003) 14:623-8. doi: 10.1046/j.0956-7976.2003.psci_1475.x

115. Nisbett RE, Aronson J, Blair C, Dickens W, Flynn J, Halpern DF, et al. Intelligence: new findings and theoretical developments. Am J Psychol. (2012) 67:130-59. doi: 10.1037/a0026699

116. Noble K, Houston S, Brito N, Bartsch H, Kan E, Kuperman J, et al. Family income, parental education and brain structure in children and adolescents. Nat Neurosci. (2015) 18:773-8. 10.1038/nn.3983. doi: 10.1038/ nn.3983

117. Kaminski JA, Schlagenhauf F. Epigenetic variance in dopamine D2 receptor: a marker of IQ malleability? the IMAGEN consortium Transl Psychiatry. (2018) 8:169. doi: 10.1038/s41398-018-0222-7

118. Lorenzo J, Barton B, Arnold SS, North KN. Cognitive features that distinguish preschool-age children with neurofibromatosis type 1 from their peers: a matched case-control study. J Pediatr. (2013) 163:147983. doi: 10.1016/j.jpeds.2013.06.038

119. Lorenzo J, Barton B, Arnold SS, North KN. Developmental trajectories of young children with neurofibromatosis type 1: a longitudinal study from 21 to 40 months of age. J Pediatr. (2015) 166:1006-12. doi: 10.1016/j.jpeds.2014.12.012

120. North K, Joy P, Yuille D, Cocks N, Hutchins P. Cognitive function and academic performance in children with neurofibromatosis type 1. Dev Med Child Neurol. (1995) 37:427-36. doi: 10.1111/j.1469-8749.1995.tb12026.x

121. Bradley RH, Corwyn RF. Socioeconomic status and child development. Annu Rev Psychol. (2002) 53:37199. doi: 10.1146/annurev.psych.53.100901.135233

122. Erdogan-Bakar E, Cinbis M, Ozyurek H, Kiris N, Altunbasak $\mathrm{S}$, Anlar B. Cognitive functions in neurofibromatosis type 1 patients and unaffected siblings. Turk $J$ Pediatr. (2009) 51:565-71. doi: 10.1016/S1090-3798(08)70376-3

Conflict of Interest: The authors declare that the research was conducted in the absence of any commercial or financial relationships that could be construed as a potential conflict of interest.

Copyright (C) 2020 Biotteau, Déjean, Lelong, Iannuzzi, Faure-Marie, Castelnau, Rivier, Lauwers-Cancès, Baudou and Chaix. This is an open-access article distributed under the terms of the Creative Commons Attribution License (CC BY). The use, distribution or reproduction in other forums is permitted, provided the original author(s) and the copyright owner(s) are credited and that the original publication in this journal is cited, in accordance with accepted academic practice. No use, distribution or reproduction is permitted which does not comply with these terms. 